\title{
The Cantharellus isabellinus species complex (Cantharellales, Hydnaceae) in tropical Africa
}

\author{
Buyck $\mathrm{B}^{1 *}$, Henkel $\mathrm{T}^{2}$ and Hofstetter $\mathrm{V}^{3}$ \\ ${ }^{1}$ Institut Systématique, Evolution, Biodiversité (ISYEB) - UMR 7205, Muséum National d'Histoire Naturelle, Sorbonne \\ Université, CNRS, Case Postale 39, 12 rue Buffon, F-75005 Paris, France \\ ${ }^{2}$ Department of Biological Sciences, Humboldt State University, Arcata, California, 95521, USA \\ ${ }^{3}$ Department of plant protection, Agroscope, Rte de Duiller, 1260 Nyon, Switzerland
}

Buyck B, Henkel T, Hofstetter V 2018 - The Cantharellus isabellinus species complex (Cantharellales, Hydnaceae) in tropical Africa. Mycosphere 9(6), 1209-1221, Doi 10.5943/mycosphere/9/6/10

\begin{abstract}
Cantharellus isabellinus is epitypified and discussed on the basis of multiple new collections from the African rain forest. These are the first collections since this species was described more than half a century ago. Phylogenetic analysis of tef- 1 sequence data confirm placement of $C$. isabellinus in $C$. subg. Rubrinus sect. Isabellinus for which it had been chosen as the type species based on morphology. Cantharellus eyssartieri is its twin species in the field but growing in Madagascar, while the very similar $C$. parvisporus stat. et comb. nov. is the closest relative of $C$. isabellinus from the surrounding miombo woodlands. Cantharellus croceifolius might represent a bisporic form of $C$. isabellinus, but has never been recollected. Cantharellus griseoisabellinus sp. nov., described here, is a somewhat similar species occurring in the same habitat as $C$. isabellinus.
\end{abstract}

Key words - molecular phylogeny / new species / Cantharellus isabellinus / Cantharellus griseoisabellinus sp. nov. / Cantharellus parvisporus stat. et comb. nov. / tef-1

\section{Introduction}

Tropical Africa is presently 'the' global hotspot for Cantharellus with nearly 50 species currently known from the region (Buyck 2016). Although new species continue to be described from tropical Africa (Buyck et al. 2012, 2016a, 2017, Buyck \& Hofstetter 2018, Das et al. 2018, De Kesel et al 2016), the most important advances in the systematics and identification of these chanterelles will come from epitypification of the many species described now sixty years ago by P. Heinemann (e.g. Heinemann 1958, see Buyck et al. 2016a, b, Buyck \& Hofstetter 2018, De Kesel et al. 2016). The present contribution on tropical African chanterelles focuses on small to medium-sized, dull grayish brown species with well-differentiated, more or less distant gill folds.

Although very few tropical African chanterelles fall into this category, for the ones that do, the lack of well-defined species concepts for the earliest described taxa has led to persistent taxonomic confusion. The key species in question is C. isabellinus Heinem., originally described from the African rain forest by Heinemann (1958). To our knowledge the species had, until now, never been recollected, but the name has been misapplied in the past (e.g. Härkönen et al. 2003) for morphologically similar species occurring in the surrounding woodlands. In addition to the need to define the species for identification purposes, establishing the correct systematic position of $C$. 
isabellinus is important as it was chosen as type species for $C$. subg. Rubrinus sect. Isabellinus Eyssart. \& Buyck, an assemblage of exclusively African chanterelles that have dull colors, a more or less squamose pileus surface composed by mostly thick-walled hyphal extremities, and all lack clamp connections. Based on macromorphology, the closest relative to $C$. isabellinus was considered to be $C$. croceifolius Heinem., described from a single Congolian specimen (Heinemann 1958). Cantharellus croceifolius has never been recollected, but should be easily recognized as it has two-spored basidia, a feature confirmed in a study of the type by Eyssartier (2001). Adding to the confusion, several similar and supposedly closely related species to the $C$. isabellinus/C. croceifolius complex were recently described: C. isabellinus var. parvisporus Eyssart. \& Buyck and $C$. tomentosus Eyssart. \& Buyck, both from the miombo woodland area (Buyck et al. 2000), and C. tomentosoides from the Gilbertiodendron rain forest (Buyck et al. 2019). Two species were recently also described from Madagascar: C. paucifurcatus Buyck \& V. Hofst. (Buyck et al. 2015) and C. eyssartieri Buyck \& Randrianjohany (Buyck \& Randrianjohany 2013), both similar to the African C. isabellinus var. parvisporus in the field, and sharing basidiospores that are slightly smaller than those of $C$. isabellinus var. isabellinus.

Considering the high infraspecific variability of both macro- and microscopic features recently demonstrated in Cantharellus (e.g. Buyck et al. 2016c, Das et al. 2018; Olariaga et al. $2015,2016)$, the morphological criteria used to distinguish between the very close taxa mentioned above might reasonably be questioned, especially in the absence of molecular data for $C$. eyssartieri and in particular for $C$. isabellinus. Due to molecular data obtained from recently collected specimens for most of the aforementioned species, the issues surrounding the $C$. isabellinus complex can now be properly addressed.

\section{Material and Methods}

\section{Collecting and macromorphology}

Basidiomata were collected during the Aug.-Nov. rainy seasons of 2014, 2016, and 2017 from the Dja Biosphere Reserve, Northwest Sector near the village of Somalomo, Upper Dja River Basin, within a two $\mathrm{km}$ radius of a base camp located at $3^{\circ} 21^{\prime} 29.8^{\prime \prime} \mathrm{N} ; 12^{\circ} 43^{\prime} 46.9^{\prime \prime} \mathrm{W}, 650 \mathrm{~m}$ a.s.l., in forests dominated by Gilbertiodendron dewevrei. Photographs and descriptions of macromorphological features were made from fresh material in the field. Colours were compared with colour plates from Kornerup \& Wanscher (1978) and are cited in parentheses. Collections were dried with silica gel. Epitype and holotype material and additional specimens are deposited in YA, Cameroon National Herbarium; PC, Museum national d'histoire naturelle, Paris, and HSC, Humboldt State University.

\section{Micromorphology}

All microscopic observations and measurements were made in ammoniacal Congo red after a short pretreatment in a $10 \%$ aqueous $\mathrm{KOH}$ solution to improve tissue dissociation and matrix dissolution. Measurements of basidiospores cite length, width and length/ width ratio (Q) in this format: (minimum-) mean minus standard deviation - mean value - mean plus standard deviation (-maximum measured); spore measurements are based on 20 spores. Microscopic features were examined and drawn with the aid of a camera lucida. Original drawings for all elements of the hymenium and pileipellis were made at a magnification of $2400 \times$.

\section{Taxon sampling and phylogenetic analyses}

Genomic DNA isolation, amplification and sequencing of newly produced sequences for the transcription elongation factor 1-alpha (tef-1) were obtained following the protocols described by Buyck et al. (2014). The other tef-1 sequences (87 Cantharellus sequences plus one outgroup sequence for Craterellus tubaeformis) used in phylogenetic analyses were part of previous publications and accessible in GenBank (Buyck et al. 2014, 2015, 2016a, b, 2019, Buyck \& Hofstetter 2018). Sequences were assembled and corrected with the software package Sequencher 
3.0 (Gene Codes Corp., USA). Tef-1 alignment was performed manually in MacClade 4.05 (Maddison \& Maddison 2002). Searches for optimal tree and branch robustness were conducted with the program PhyML (Guindon \& Gascuel 2003), with the searches starting from a distancebased tree and using GTR evolutionary substitution model with the proportion of invariable sites, the gamma shape parameter and the number of substitution categories estimated during the search. Three independent runs were conducted to check for convergence toward the same likelihood value. Using the same program, maximum likelihood branch support (ML-bs) was estimated based on 500 bootstrap replicates and was considered significant when $\geq 70 \%$ (Mason-Gamer \& Kellog 1996, Alfaro et al. 2003).

\section{Results}

\section{Phylogenetic results}

Nine tef-1 sequences were newly produced for this study (see Fig. 1 for GenBank accession numbers). The analyzed dataset included 96 tef-1 sequences and 629 nucleotide positions after exclusion of three spliceosomal introns. The most likely tree (Fig. 1) delimited the same clades as the previous 4-locus combined analyses of Buyck et al. (2014) except for C. subcyanoxanthus and close relatives (see Buyck et al. 2014, clade 4c) that cluster here with subg. Afrocantharellus (clade 6) with high support (ML-bs $=100 \%$ ) while they were part of subg. Parvocantharellus (clade 4) in Buyck et al. (2014) study. Phylogenetic analyses (Fig. 1) indicated that the newly described taxa, $C$. parvisporus stat. et comb. nov. and C. griseoisabellinus sp. nov., as well as C. eyssartieri and the epitypified $C$. isabellinus, all clustered, however without significant support (ML-bs $=69 \%$ ), in a clade corresponding to Cantharellus subgen. Rubrinus sect. Isabellinus (clade $2 \mathrm{a}$ in Buyck et al. 2014). Whithin that clade, the monophyly of $C$. isabellinus (ML-bs $=100 \%$ ), C. parvisporus (MLbs $=99 \%)$ and $C$. eyssartieri was highly supported (ML-bs $=100 \%)$. Even if basal relationships within subgen. Rubrinus sect. Isabellinus remained unresolved, C. griseoisabellinus (ML-bs $=100$ $\%$ ) is clearly a phylogenetically unique species within the group nesting between two significantly supported subclades, one including C. eucalyptorum and C. tanzanicus (ML-bs $=100 \%$ ) and the other C. luteopunctatus, $C$. densilamellatus, C. tricolor and C. albidolutescens (ML-bs = $93 \%$ ).

\section{Taxonomy}

Cantharellus isabellinus Heinem. Bulletin du Jardin Botanique de l'État à Bruxelles 28: 399. 1958.

Figs 2-3

Holotype - DEMOCRATIC REPUBLIC OF THE CONGO. Binga, dispersed or in troops on the soil of the dry forest, Aug. 1934, M. Goossens Fontana 977 et icon. (BR); ibid., avril 1928, M. Goossens Fontana 699 (paratype).

Original diagnosis - Pileus carnosus, convexus deinde infundibuliformis, fuscus, tomentosofurfuraceus. Stipes sursum albidus, deorsum alutaceus. deinde fuscus, apice furfuraceus, mycelio ochraceo. Lamellae griseorosae. distantes, angustiusculae, paulum furcatae, leviter intervenulatae. Caro mollis, fracta lutescens. Sporae luteolae, 7,8-9 × 5,2-6,6 $\mu \mathrm{m}$

Original description - (freely translated from French): "Pileus 4-6 cm diam., fleshy in the center, thin toward the margin, depressed-infundibuliform with convex, lobed margin; surface tomentose-furfuraceous [minutely squamulose-hirsute], adnate, pale brown to yellowish gray. Stipe ca. $60 \times 7 \mathrm{~mm}$, cylindrical or very slightly widening toward the base, regular, first whitish at the top and dirty ochraceous near the base, then becoming entirely yellowish gray, hirsute in the upper part, solid, with some bright ochre mycelium at the soil interface. Hymenophore composed of rather spaced gill folds ( e.g. $\mathrm{L}+\mathrm{l}=11 / \mathrm{cm}$ ), quite narrow, up to $3 \mathrm{~mm}$ high, strongly decurrent, unequal, sometims forked, irregularly and weakly veined at their base, dirty pinkish, [first orangish toward the edge]. Context soft, fibrous, yellowing when cut. Odor acrid (?). Taste bitter (?). Spore print pale ochraceous pink. Exsiccatum entirely brown, ochraceous. 


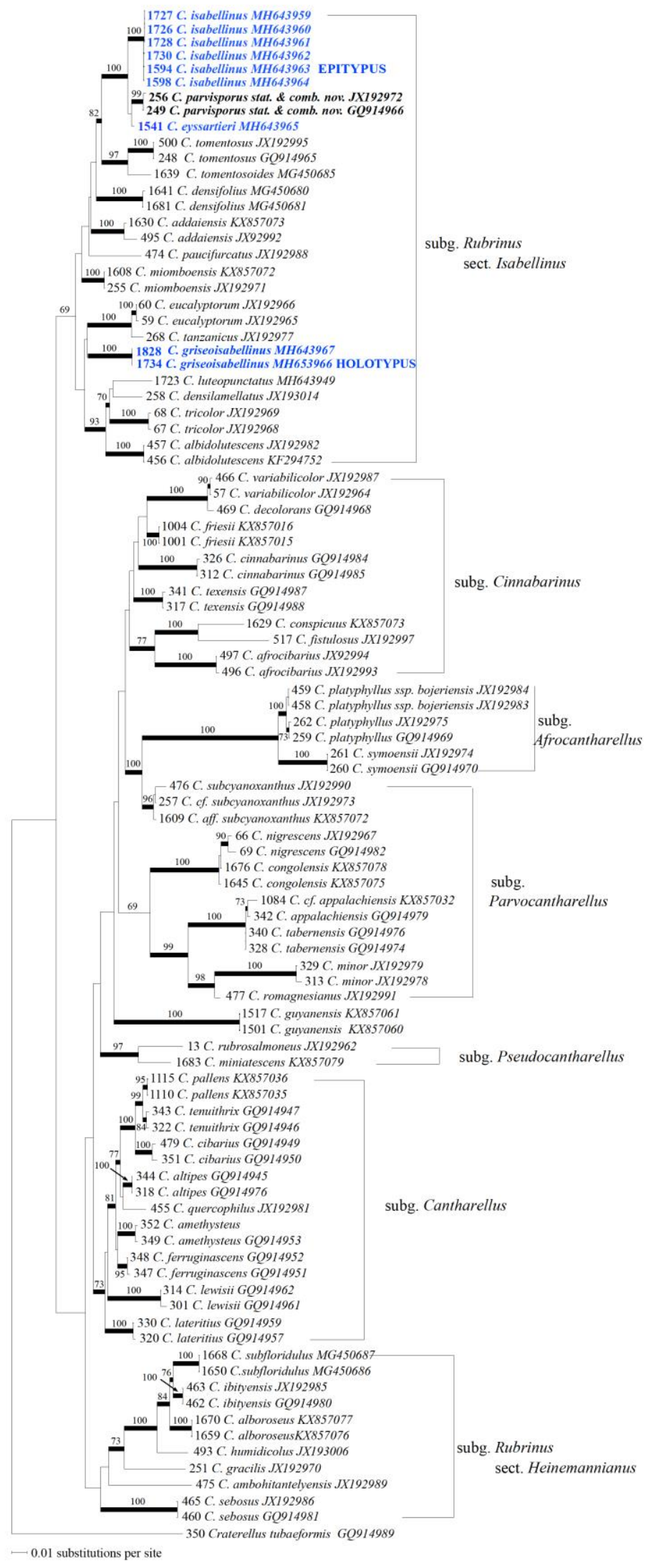

Figure 1 - Most likely tree inferred by analyses of 96 Tef-1 sequences. Names of taxa are preceded by their extraction number and followed by their GenBank accession. The taxa discussed are in bold and sequences newly produced for this study are in blue. Branches that received significant bootstrap support are in bold and ML-bs values indicated along the branches. Infrageneric delimitations as inferred by Buyck et al. (2014) are reported. 
Spores yellowish, 7.8-9 $\times$ 5.2-6.6 $\mu \mathrm{m}$, shortly ellipsoid, with straight or very slightly depressed adaxial side, thin-walled, not amyloid, regularly with refringent inclusions; apiculus small. Basidia $65 \times 7 \mu \mathrm{m}$ for ex. [45-55 × 8-11 $\mu \mathrm{m}$ ], four-spored. Hymenium accrescent. Subhymenium ramified. Pseudoparenchyma distinct in cap and stipe context, compact. Pileipellis composed of cylindrical hyphae, 4.5-11 $\mu \mathrm{m}$ wide, yellowish, thin-walled; squamae of the pileus surface composed of chains of more or less thick-walled, brown cells, rather long and 40-65 $\times 8$-13 $\mu \mathrm{m}[25-70 \times 7-18 \mu \mathrm{m}]$. Clamp connections probable, but difficult to observe. Oleiferous hyphae very large, up to $30 \mu \mathrm{m}$ diam., locally abundant in the context. (parts in between parentheses [ ] relate to observations on paratype)".

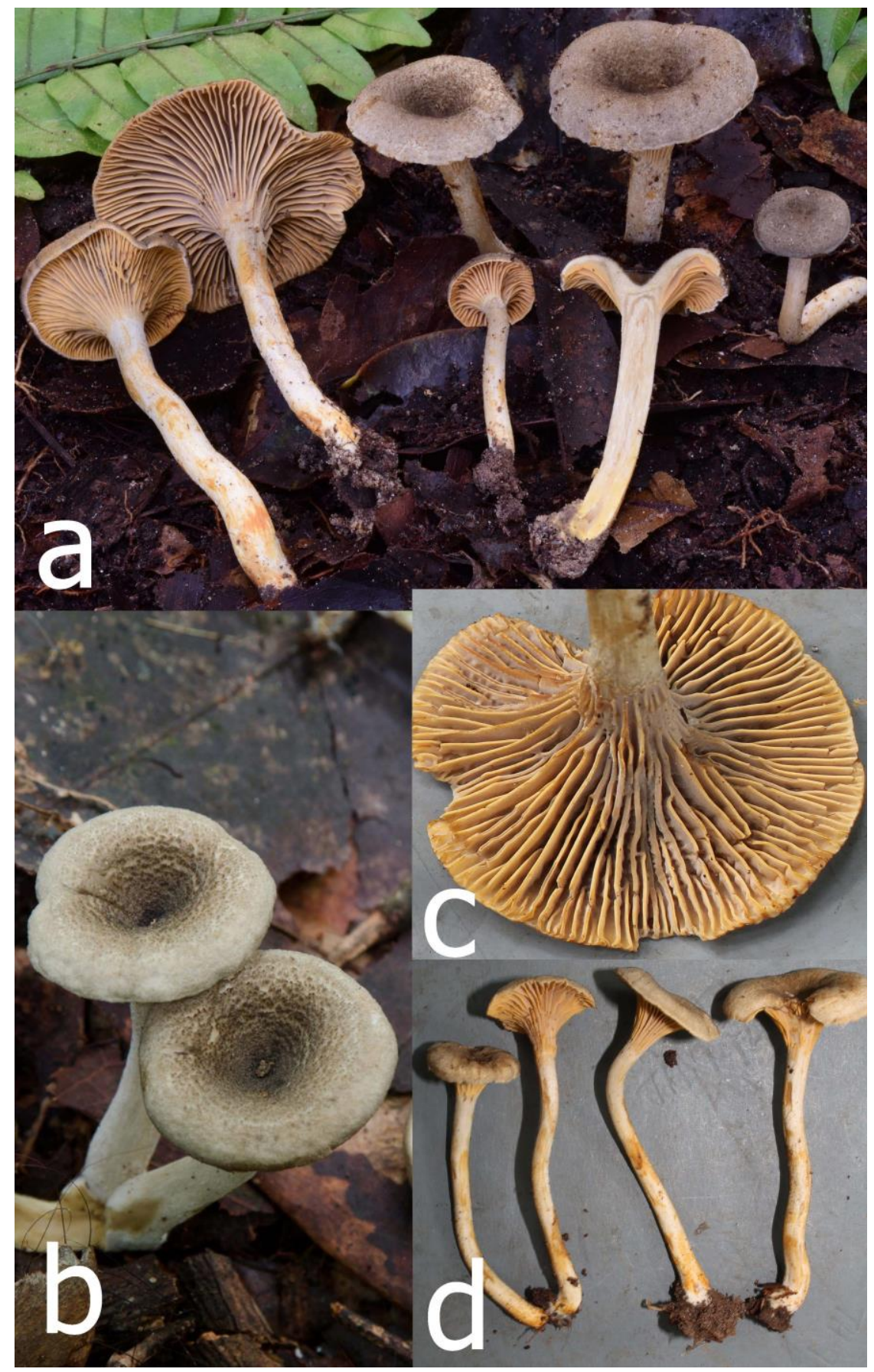

Figure 2 - Cantharellus isabellinus. a-b Field habit (a: N. Siegel NS2241, b: Dja31). c Detail of hymenophore, notice the deeply decurrent, rather thick gill folds having vertical ribs on their sides, the abundant shorter gills and dispersed forkings (TH10501). d Basidiomata (TH9989). Photo credits: N. Siegel (a), T. Henkel (c, d) 


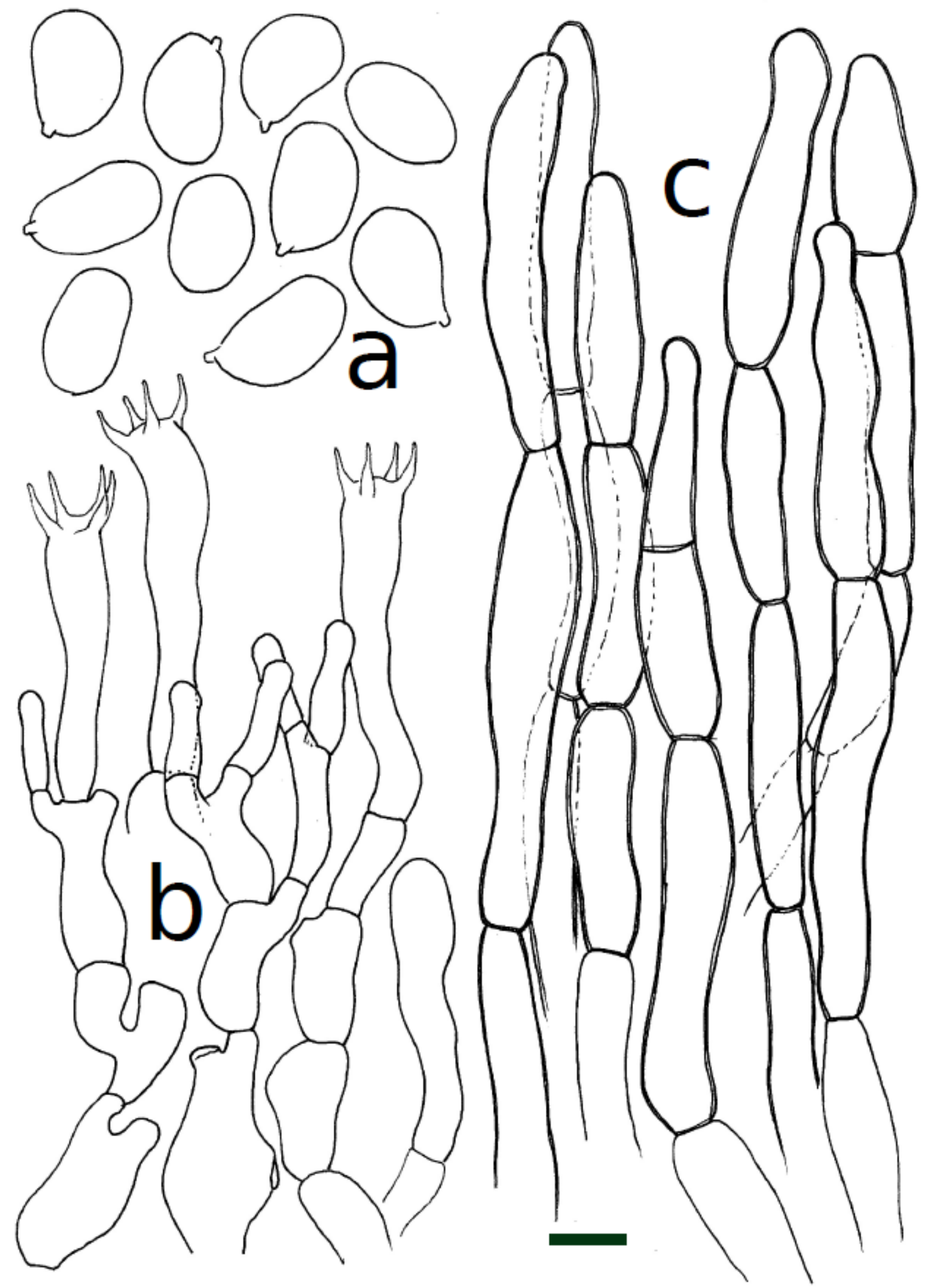

Figure 3 - Cantharellus isabellinus (epitype). Microscopic features: a spores. b basidia and basidiola. $\mathrm{c}$ hyphal extremities of the pileipellis without indication of brown pigment. Scale bar $=$ $10 \mu \mathrm{m}$ but only $5 \mu \mathrm{m}$ for spores. Drawings B Buyck. 


\section{Epitype description}

Mycobank number: MBT384954

Basidiomata small, solitary, in pairs or small groups. Pileus 10-23 mm diam., plane with central depression; margin entire, smooth to irregularly and shallowly undulating, inrolled, never becoming uplifted; surface covered by fibrillose tuffs, denser toward center, dark brownish green (4C4), becoming paler (4E-F4) toward the margin with expansion of the pileus. Hymenophore deeply decurrent, composed of well-developed and rather thick gill folds, without interstitial venation but often developing vertical ribs on their sides, unequal, rarely to poorly forking except closer to the pileus margin, closely arranged near the pileus margin because of the presence of forkings and many shorter gill folds, more spaced toward the stipe, $2 \mathrm{~mm}$ high, ochraceous (5B3) particularly near the gill edge, with faint pinkish tinges on sides especially when older, turning deep yellowish when injured, with blunt, smooth edges. Stipe typically long and slender compared to the pileus diam., 25-35 $\times 2-4 \mathrm{~mm}$, glabrous with longitudinal striations, often also whitish powderypubescent toward apex, subcylindrical or slightly widening at the base, off-white, strongly bruising orange-brown (5C7-8). Context white, sometimes yellowing near the stipe base, $2 \mathrm{~mm}$ thick just outside the pileus center. Smell typical but faint. Taste mild to slightly bitter. Spore print not obtained.

Basidiospores ellipsoid, (8.1)8.3-8.73-9.2(9.6) $\times(5.4) 5.6-5.84-6.1(6.3) \mu \mathrm{m}, \mathrm{Q}=(1.3) 1.4-$ 1.50-1.6(1.7), smooth. Basidia rather short, 37-57 × 7-8(9) $\mu \mathrm{m}$, slightly clavulate, bearing (3-)4(5) robust sterigmata. Subhymenium pseudoparenchymatous, composed of variably inflated, ramifying cells. Cystidia none. Pileipellis a loose tissue composed of hyphal terminations forming long chains of cells that cling together to form ascending rhizoid-like structures on top of the pileus surface; the two to five distal cells with brown pigment, mostly 6-12 $\mu \mathrm{m}$ wide, with cell walls not exactly thin-walled but clearly refringent to slightly thickened (at least compared to the hyphae below); terminal cells mostly (25)30-50 $\mu \mathrm{m}$ long, subcylindrical or slightly fusiform or even weakly ampullaceous, often subapically faintly constricted or simply narrowing. Clamp connections absent.

Habit, habitat and distribution - Scattered on litter mat of forest floor in Gilbertiodendron dewevrei monodominant forest; known from the central Congo Basin and southern Cameroon.

\section{Examined and sequenced material:}

Epitype: Cameroon, East Province, Dja Biosphere Reserve, Northwest Sector near the village of Somalomo, Upper Dja River Basin, within $2 \mathrm{~km}$ radius of Dja base camp located at $3^{\circ} 21^{\prime} 29.8^{\prime \prime}$ $\mathrm{N} ; 12^{\circ} 43^{\prime} 46.9^{\prime \prime} \mathrm{W}$, in monospecific upper story Gilbertiodendron dewevrei forest, on soil amidst thick litter layer, $650 \mathrm{~m}$ alt, coll. T. Henkel and coll., 23 Aug 2014, 1598 / Henkel DJA31 (YA, epitypus hic designatus, duplicates PC0713878, HSC G1252);

Other examined and sequenced collections: Cameroon, ibid., 2 Sept 2014, 1594 / Henkel 9989 (PC0713874, HSC G1253); 14 Nov 2016, 1726 / Henkel 10311 (PC0142508, HSC G1254), 1727 / Henkel 10312 (PC0142509, HSC G1255); 29 Nov 20161728 / Henkel 10337 (PC0142512, HSC G1256), 1730 / 3 Dec 2016, Henkel 10361 (PC 0142514, HSC G1257); 24 Aug 2017, 1833 / N. Siegel 2241 (PC0125046, HSC G1258); 6 Sept 2017, 1820 / Henkel 10472 (PC0125033, HSC G1259); 14 Sept 2017, 1824 / Henkel 10501, PC0125037, HSC G1260)

Commentary: The epitype chosen for $C$. isabellinus overall corresponds very well to the original description, even though our specimens are considerably smaller, with pilei usually $\leq 2 \mathrm{~cm}$ diam. versus 4-6 cm diam. in the original description. Among all the examined collections, only Siegel 2241 had a pileus diameter noted as $13-46 \mathrm{~mm}$ wide. Pileus size also does not exceed $4 \mathrm{~cm}$ in any of the close relatives of $C$. isabellinus (except for $C$. griseoisabellinus described here, and which is otherwise quite different in the field and phylogenetically more distant). Basidioma sizes are a recurrent problem with many of Heinemann's descriptions (see Buyck et al. 2016a), and we do not attach too much importance to this difference, given that size is infraspecifically highly variable for many chanterelles (Buyck et al. 2014). Size differences notwithstanding, the epitype and holotype share most of the other salient features: well-developed and relatively high, unequal 
and hardly forking gills folds of identical color, strong yellowing context turning finally to rusty upon exposure, and a dark, dirty brown pileus with greenish tinges as shown in the original water color (Heinemann 1959). The 'irregular and weak veins' mentioned by Heinemann (1.c.) for the gill-folds are not comparable to what we normally refer to as 'anastomosing gill folds' seen, for example,, in the Afrotropical C. miniatescens (Buyck et al. 2016b) and C. luteopunctatus (Buyck et al. 2019. In C. isabellinus, the veins are restricted to the vertical sides of the gills, where they form a thick, rib-like pattern on both gill sides. This pattern does not extend to the surface that lies in between two gill-folds and hence never forms the typical alveolar pattern observed in strongly anastomosing species.

The microscopic similarities between the epitype and holotype are even more convincing (compare also with Heinemann 1958, fig. 38): hyphal extremities in both are not exactly thinwalled, but rather 'refringent' (hence the mention of "yellowish" cell walls by Heinemann). These cells are of similar form and diameter in both types (compare with Heinemann 1958, fig. 38C) and are in both cases amply filled with brown pigment. The epitype and holotype also share ellipsoid basidiospores of identical size and both have principally 4-spored basidia (though not exclusively 4-spored as noted by Heinemann). Heinemann's original description mentioned a probable presence of clamp connections, but this was contradicted in the type study by Eyssartier (2001) and their absence in the epitype and other specimens is here confirmed.

Cantharellus isabellinus is macroscopically well characterized judging by the similarity of all collected specimens. In the rain forest area it cannot be confused with any other chanterelle, except perhaps for $C$. tomentosoides (see Buyck et al. 2019). Both species indeed share exactly the same aspect of pileus surface (see Buyck et al. 2019 as well as similar colors and overall habit, but $C$. isabellinus has more widely spaced gill folds and larger basidiospores (see Table 1).

Cantharellus croceifolius Heinem. is another rain forest chanterelle of similar size that was suggested to be the closest relative of $C$. isabellinus by Heinemann (1958), differing essentially in its bisporic basidia, a feature confirmed by the type study of Eyssartier (2001). Apart from a slightly paler overall color of $C$. croceifolius, all of its other features are shared with C. isabellinus, including the rather small basidia, identical basidiospores, and similar pileipellis hyphae (for ex., our collection TH10337 for $C$. isabellinus shares identical spore size with the holotype of $C$. croceifolius - see Table 1). The number of basidiospores formed per basidium is typically variable in most chanterelles, although there is a clear tendency in most species for a particular number of basidiospores per basidium, such as predominantly 4-spored or 5-6-spored species (see Buyck et al. 2014). Exclusively 2 -spored chanterelles are exceptional and this feature has so far been described for a single other species, the African C. solidus (see De Kesel et al. 2011). Within the cantharelloid clade, however, it is the normal condition for nearly all Clavulina species. Considering the identical morphology shared by both taxa, and the fact that $C$. isabellinus is a predominantly four-spored species, we think it is possible that $C$. croceifolius represents a twospored form of the same taxon.

Outside of the rain forest area, there are a number of morphologically similar species that all appear to be close relatives of $C$. isabellinus. Among these taxa is C. eyssartieri Buyck \& Randrianjohany, a nearly identical species described from monospecific Uapaca densifolia forest on the mountain crests of the Central Plateau in Madagascar (Buyck \& Randrianjohany 2013) and initially distinguished from $C$. isabellinus on the basis of its slightly smaller basidiospores. However, the substantially narrower and more sinuous, clearly thin-walled terminal cells in the pileipellis of $C$. eyssartieri constitute a better feature to distinguish it morphologically from $C$. isabellinus. The Malagasy $C$. paucifurcatus is another species that shares a very similar general stature with $C$. isabellinus, but it is much paler and has a browning, not rusty yellowing context; furthermore, it has a different ecology being associated with Uapaca bojeri woodland on the Central Plateau of Madagascar (Buyck et al. 2015). Microscopically, it shares with C. isabellinus identical basidiospores (see Table 1), but differs from it in its narrow and distinctly thick-walled hyphal extremities in the pileipellis. Additionally, at the species level both $C$. eyssartieri and $C$. paucifurcatus are phylogenetically distinct from C. isabellinus (Fig. 1). 
Table 1 Comparison of obtained spore measurements for the discussed species. Holotype measurements for species not further discussed here are taken from the original descriptions.

\begin{tabular}{|c|c|c|c|}
\hline & Spore length & Spore width & Q ratio \\
\hline \multicolumn{4}{|l|}{ C. isabellinus } \\
\hline Holotype (Heinem 1958) & $7.8-9$ & $5.2-6.6$ & \\
\hline Holotype (Eyssart 2001) & $8-8.78-10$ & $5-5.82-6.5$ & $1.4-\mathbf{1 . 5 1}-1.7$ \\
\hline Epitype T Henkel DJA31 & $(8.1) 8.3-8.73-9.2(9.6)$ & $(5.4) 5.6-\mathbf{5 . 8 4}-6.1(6.3)$ & $(1.3) 1.4-\mathbf{1 . 5 0}-1.6(1.7)$ \\
\hline T.Henkel 10311 & $(7.5) 8.0-8.67-9.3(10.2)$ & $(5.2) 5.4-5.68-5.9(6.2)$ & $\begin{array}{l}(1.3) 1.43-\mathbf{1 . 5 3}- \\
1.6(1.7)\end{array}$ \\
\hline T.Henkel 10337 & $(7.5) 7.9-8.40-8.8(9.4)$ & $(5.2) 5.5-6.2-6.9(8.1)$ & $(1.0) 1.2-1.36-1.5(1.5)$ \\
\hline T.Henkel 9989 & $(6.7) 7.6-8.19-8.8(9.2)$ & (4.8)4.9-5.24-5.6(6.0) & (1.3)1.4-1.57-1.7(1.8) \\
\hline N. Siegel 2241 & $(7.5) 7.8-8.28-8.7(9.2)$ & $(5.0) 5.3-5.65-6.1(6.5)$ & (1.3)1.4-1.47-1.6(1.7) \\
\hline \multicolumn{4}{|l|}{ C. parvisporus } \\
\hline Holotype & (7)7.5-8.1-8.5(9) x & (4)4.4-4.75-5.1 & $(1.5) 1.6-1.71-1.8(1.9)$ \\
\hline \multicolumn{4}{|l|}{ C. eyssartieri } \\
\hline Holotype & $(7) 7.25-7.73-8.25(8.5)$ & $(4.7) 5-5.4-6(6.5)$ & $(1.1) 1.3-1.44-1.5(1.6)$ \\
\hline \multicolumn{4}{|l|}{ C. tomentosus } \\
\hline Holotype & $6-6.98-8$ & $3.5-3.92-4.5$ & $1.5-1.79-2.1$ \\
\hline \multicolumn{4}{|l|}{ C. tomentosoides } \\
\hline Holotype & $\begin{array}{l}(5.8-) 6.0-6.36-6.7(- \\
7.1)\end{array}$ & $\begin{array}{l}\text { (3.9-)4.0-4.27-4.5(- } \\
5.0)\end{array}$ & $\begin{array}{l}(1.3-) 1.4-1.49-1.6(- \\
1.7)\end{array}$ \\
\hline \multicolumn{4}{|l|}{ C. croceifolius } \\
\hline Holotype (Eyssart. 2001) & $7-8.36-10$ & $5.5-6.10-7$ & $1.1-1.32-1.5$ \\
\hline \multicolumn{4}{|l|}{ C. griseoisabellinus } \\
\hline $\begin{array}{l}\text { Holotype T.Henkel } \\
10387\end{array}$ & $(6.0) 6.3-6.95-7.6(8.5)$ & $(4.2) 4.5-4.93-5.4(6.5)$ & $1.3-\mathbf{1 . 4 2 - 1 . 5 ( 1 . 7 )}$ \\
\hline T.Henkel 10533 & $(6.2) 6.3-6.88-7.4(7.9)$ & $(4.2) 4.4-\mathbf{4 . 8 6}-5.3(5.6)$ & (1.3)1.3-1.42-1.5(1.6) \\
\hline T.Henkel DJA137 & $(6.2) 6.7-7.10-7.5(7.7)$ & $(4.2) 4.3-\mathbf{4 . 6 1}-4.9(5.2)$ & (1.4)1.4-1.54-1.7(1.9) \\
\hline \multicolumn{4}{|l|}{ C. paucifurcatus } \\
\hline Holotype & $(7.9) 8.3-8.8-9.3(9.6)$ & $(5.0) 5.2-5.7-6.2(6.7)$ & $(1.3) 1.4-\mathbf{1 . 5}-1.6(1.8)$ \\
\hline
\end{tabular}

Cantharellus isabellinus var. parvisporus, Eyssart. \& Buyck, described from miombo woodland in Tanzania (Buyck et al. 2000), was distinguished from the type variety no only because of its different ecology, but also on the basis of the slightly smaller, particularly somewhat narrower and thus more elliptical basidiospores, measuring $<5 \mu \mathrm{m}$ wide. Our phylogenetic analysis (Fig. 1) shows that $C$. isabellinus var. parvisporus is closely related to, but phylogenetically distinct from $C$. isabellinus and merits recognition at the species level:

Cantharellus parvisporus (Eyssart. \& Buyck) Buyck \& V. Hofst. comb. et stat. nov.

Mycobank number: MB 829074

Basionym: Cantharellus isabellinus var. parvisporus Eyssart. \& Buyck, in Buyck et al., Nova Hedwigia 71(3-4): 494. 2000

Cantharellus griseoisabellinus Buyck, Henkel \& V. Hofst. sp. nov.

Figs 4-5

Mycobank number: MB 829073

Etymology - refers to the superficial similarity with $C$. isabellinus, from which it differs, amongst other characters, by the more grayish overall color, hence its name.

Diagnosis - differs from $C$. isabellinus in its slightly taller, more robust habit, more irregularly wavy to folded pileus, the absence of strong staining reactions on context and surface of fruiting bodies, the interveined, distinctly paler gill folds, smaller spores and more thick-walled, 
undulate-sinuous hyphal extremities that are not clustering in trichoid-like structures at the pileus surface and lacking brown pigment.

Basidioma solitary, fleshy. Pileus $67 \mathrm{~mm}$ diam., strongly depressed in the center and with very irregular, lobed, downturned margin that is finely crenulate; surface radially coarsely striate, dark greyish brown (6D4-5), in the center areolate-squamulose and covered with dense, concolorous, more or less appressed tufts on an off-white, isabelline background (4A1-2). Hymenophore composed of well-differentiated gill folds, shortly decurrent, forking sparsely at various distances from the stipe, transversely interveined in between the gill folds except closer to the pileus margin, often also vertically ribbed on their sides, greyish $\tan (5 \mathrm{~B} 2-3)$, unchanging, with even, concolorous edges. Stipe $65 \times 12 \mathrm{~mm}$, subcylindrical, narrowing downward, glabrous, offwhite with some orange-cream tinges (4A2-3) in the lower halve, not hollowing. Context off-white to pale cream, $2 \mathrm{~mm}$ thick at mid radius, very slowly turning yellowish orange. Taste not as fruity as in other chanterelles. Odor absent. Spore print not obtained.

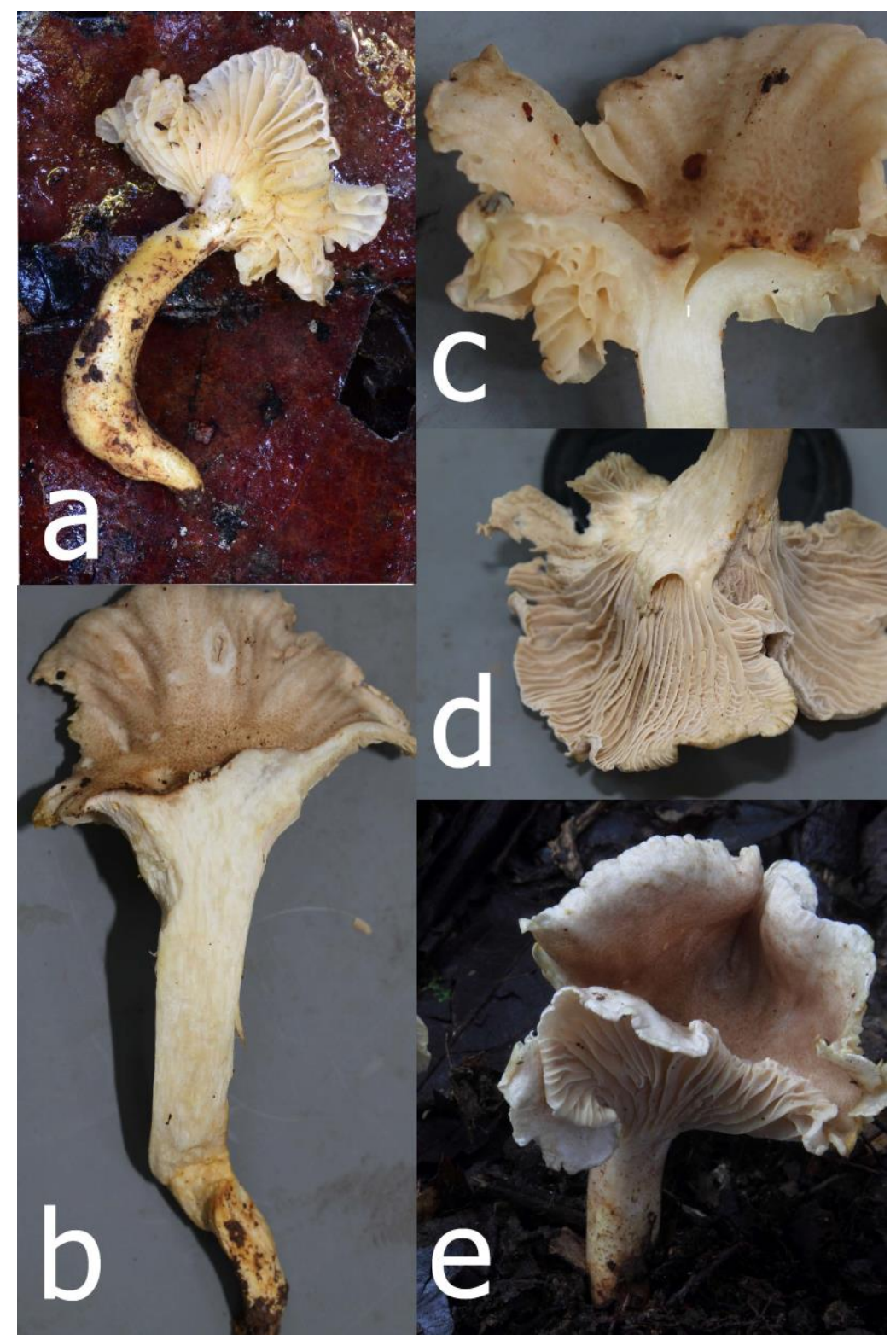

Figure 4 - Cantharellus griseoisabellinus. a Field habit (TH 10533). b Section through fruiting body (from holotype). c Detail showing the squamulose pileus surface (TH 10533). d Details of hymenophore, notice the different color compared to TH 10533 (a) and the deeply decurrent, rather thick gill folds having vertical ribs on the sides as well as connecting anastomoses in between (holotype). e Field habit (TH DJA137). Photo credits T. Henkel. 

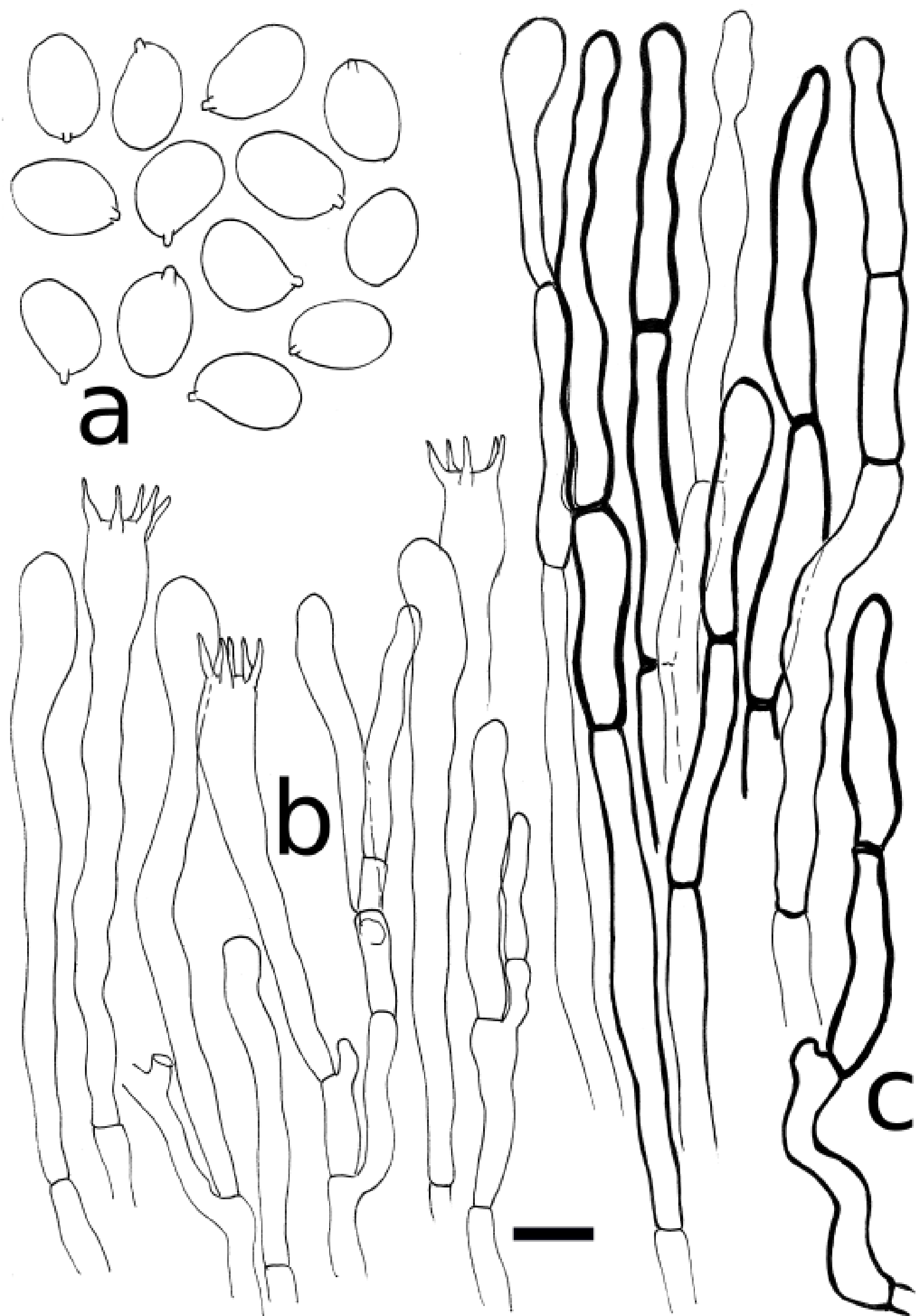

Figure 5 - Cantharellus griseoisabellinus (holotype, TH10387). Microscopic features: a. spores; b. basidia and basidiola; c. slightly sinuous-undulate hyphal extremities of the pileipellis. Scale bar $=$ $10 \mu \mathrm{m}$ but only $5 \mu \mathrm{m}$ for spores. Drawings B Buyck. 
Basidiospores ellipsoid, (6.0)6.3-6.95-7.6(8.5) × (4.2)4.5-4.93-5.4(6.5) $\mu \mathrm{m}, \mathrm{Q}=1.29-1.42$ 1.54(1.73), smooth. Basidia long and slender, (52)75-90 × 7-8 $\mu \mathrm{m}$, narrowly clavulate, (4)5(6)spored; basidiola very slender and cylindrical. Subhymenium filamentous. Pileipellis composed of strongly septate, pale yellow hyphal extremities, composed of rather narrow cells, not clustering in trichoid-like structures but intricately intermixed, mostly 4-8 $\mu \mathrm{m}$ diam., with thin to moderately thickened walls (up to $1 \mu \mathrm{m}$ ); terminal cells mostly 30-60 $\mu \mathrm{m}$ long, often slightly sinuous or undulate in outline, narrowly cylindrical, clavate or apically constricted to almost subcapitate.

Clamp connections absent from all tissues.

Material examined - Cameroon, East Province, Dja Biosphere Reserve, Northwest Sector near the village of Somalomo, Upper Dja River Basin, within $2 \mathrm{~km}$ radius of Dja base camp located at $3^{\circ} 21^{\prime} 29.8^{\prime \prime} \mathrm{N} ; 12^{\circ} 43^{\prime} 46.9^{\prime \prime} \mathrm{W}$, in monospecific upper story Gilbertiodendron dewevrei forest, on soil amidst thick litter layer, $650 \mathrm{~m}$ alt, coll. T. Henkel and coll., $12 \mathrm{Dec}$ 2016, 1734 / Henkel 10387 (YA holotypus!, isotypes PC0142518, HSC G1261); ibid., 22 Sept 2017, 1828 / Henkel 10533 (PC0125041, HSC G1262); 22 Sept 2014, 1603 / Henkel DJA137 (PC0713884, HSC G1263)

Commentary: Cantharellus griseoisabellinus differs from C. isabellinus in its slightly taller, more robust stature, very irregular folded-wavy pileus margin, absence of strongly staining tissues, distinctly intervenose gill folds, overall paler colors, smaller basidiospores and narrower, more thick-walled and undulate-sinuous pileipellis hyphal extremities that do not form a woolly tissue.

While the phylogenetic analysis clearly indicated that $C$. griseoisabellinus is a distinct species within subgen. Rubrinus sect. Isabellinus, its relationship to any other species in the clade is poorly supported, but our analysis suggests that it belongs to a different subclade in the section (Fig. 1).

\section{Acknowledgements.}

Funding was provided to T.W. Henkel by National Geographic Society's Committee for Research and Exploration grant 9235-13 and National Science Foundation grant DEB-1556338. In Cameroon the Ministry of Research and Scientific Innovation issued research permits. The Conservator of the Dja Biosphere Reserve, Mr. Ndinga Hilaire, and his staff greatly assisted the fieldwork in the Dja. Field assistance in Cameroon was also provided by Mei Lin Chin, Todd Elliott, Camille Truong, Cathie Aime, Rachel Koch, Carolyn Delevich, Kennan Mighell, Jessie Uehling, Noah Siegel, Alamane Gabriel (a.k.a. Sikiro), and Essambe Jean-Pierre (a.k.a. Papa Chef).

\section{References}

Alfaro M, Zoller S, Lutzoni F. 2003 - Bayes or bootstrap? A simulation study comparing the performance of Bayesian Markov chain Monte Carlo sampling and bootstrapping in assessing phylogenetic confidence. Molecular Biology and Evolution 20: 255-266.

Buyck B. 2016 - Editorial Special Issue: Cantharellus. Towards completing the world inventory of Cantharellus. Cryptogamie Mycologie 37: 255-258

Buyck B, De Crop E, Verbeken A, Hofstetter V. 2016a - Untangling the Central African Cantharellus sect. Tenues: Cantharellus minutissimus sp.nov. and epitypification of Cantharellus alboroseus. Cryptogamie, mycologie 37(3): 329-344.

Buyck B, Duhem B, Das K, Jayawardena RS et al. 2017 - Fungal Biodiversity Profiles 21-30. Cryptogamie Mycologie 38(1):101-146

Buyck B, Eyssartier G, Kivaisi A. 2000 - Addition to the inventory of the genus Cantharellus (Basidiomycotina, Cantharellaceae) in Tanzania. Nova Hedwigia 71(3/4): 491-502.

Buyck B, Henkel TW, Dentinger BTM, Séné O, Hofstetter V. 2016b - Multigene sequencing provides a suitable epitype, barcode sequences and a precise systematic position for the enigmatic African Cantharellus miniatescens. Cryptogamie Mycologie 37(3): 269-282.

Buyck B, Henkel TW, Hofstetter V. 2019 - Epitypification of the Central African Cantharellus densifolius and $C$. luteopunctatus allows for the recognition of at least two additional species. Mycokeys (accepted) 
Buyck B, Hofstetter V. 2018 - Cantharellus subg. Pseudocantharellus (Hydnaceae, Cantharellales) revisited: one epityfication, one new synonym and one new species. Mycosphere 9 (1):141148.

Buyck B. Kauff F, Randrianjohany E, Hofstetter V. 2015 - Sequence data reveal a high diversity of endemic Cantharellus associated with native vegetation in Madagascar. Fungal Diversity 70(1): 189-208.

Buyck B, Kauff F, Couloux A, Hofstetter V. 2012 - Molecular evidence for novel Cantharellus (Cantharellales, Basidiomycota) from tropical African miombo woodland and a key to all tropical African chanterelles. Fungal Diversity 58: 281-298

Buyck B, Kauff F, Eyssartier G, Couloux A, Hofstetter V. 2014 - A multigene world phylogeny for Cantharellus. Fungal Diversity 64: 101-121.

Buyck B, Olariaga I, Justice J, Lewis DP, Roody W, Hofstetter V. 2016c - The dilemma of species recognition in the field when sequence data are not in phase with phenotypic variability. Cryptogamie, Mycologie 37(3): 367-389.

Buyck B, Randrianjohany E. 2013 - Cantharellus eyssartieri sp.nov. (Cantharellales, Basidiomycota) from monospecific Uapaca ferruginea stands near Ranomafana (eastern escarpment, Madagascar). Cryptogamie, Mycologie 34 (4): 29-34.

Das K, Rossi W, Leonardi M, Ghosh A, et al. 2018 - Fungal Biodiversity Profiles 61-70. Cryptogamie, Mycologie 39(4): 381-418.

De Kesel A, Amalfi M, Kasongo B, Yorou NS et al. 2016 - New and interesting Cantharellus from tropical Africa. Cryptogamie, Mycologie 37(3): 283-327.

De Kesel A, Yorou NS, Buyck B. 2011 - Cantharellus solidus, a new species from Benin (WestAfrica) with a smooth hymenium. Cryptogamie, mycology 32(3):1-8

Eyssartier G. 2001 - Vers une monographie du genre Cantharellus Adans.:Fr. 259 p. Dissertation, National History Museum, Paris.

Guindon S, Gascuel O. 2003 - A simple, fast, and accurate algorithm to estimate large phylogenies by maximum likelihood. Systematic Biology 52: 696-704.

Härkönen M, Niemelä T, Mwasumbi L. 2003 - Tanzanian mushrooms. Edible, harmful and other fungi. Norrlinia 10: 1-200.

Heinemann P. 1958 - Champignons récoltés au Congo Belge par Madame Gossens-Fontana. III. Cantharellineae. Bulletin du jardin botanique de l'État Bruxelles 28: 385-438.

Heinemann P. 1959 - Cantharellineae. Flore iconographique des champignons du Congo 8: 153165, pl. 26-28.

Kornerup A, Wanscher JH. 1978 - Methuen handbook of colour. 3rd ed. London: Methuen \& Co. Ltd. $252 \mathrm{pp}, 30 \mathrm{pl}$.

Maddison DR, Maddison WP. 2002 - MacClade: Analysis of Phylogeny and Character Evolution, version 4.05. Sinauer Associates Inc., Sunderland, Massachusetts, USA

Mason-Gamer, R., Kellog E. 1996 - Testing for phylogenetic conflict among molecular data sets in the tribe Triticeae (Gramineae). Systematic Biology 45, 524-545.

Olariaga I, Buyck B, Esteve-Raventos F, Hofstetter V et al. 2015 - Assessing the taxonomic identity of white and orange specimens of Cantharellus: occasional colour variants or independent species? Cryptogamie Mycologie 36(3): 287-300.

Olariaga I, Moreno G, Manjoni JL, Salcedo I et al. 2016 - Cantharellus (Cantharellales, Basidiomycota) revisited in Europe through a multigene phylogeny. Fungal Diversity 83(1): 263-292. 